\title{
Systematic Review with Meta-Analysis: Low-Level Alcohol Consumption and the Risk of Liver Cancer
}

\author{
Hana Park ${ }^{1}$, Seung Kak Shin ${ }^{2}$, Ijin Joo ${ }^{3}$, Do Seon Song ${ }^{4}$, Jeong Won Jang ${ }^{4}$, and Joong-Won Park ${ }^{5}$ \\ ${ }^{1}$ Health Screening and Promotion Center, Asan Medical Center, University of Ulsan College of Medicine, Seoul, ${ }^{2}$ Department of Internal \\ Medicine, Gachon University Gil Medical Center, Gachon University College of Medicine, Incheon, ${ }^{3}$ Department of Radiology, Seoul National \\ University Hospital, ${ }^{4}$ Department of Internal Medicine, College of Medicine, The Catholic University of Korea, Seoul, and ${ }^{5}$ Center for Liver \\ Cancer, National Cancer Center, Goyang, Korea
}

Background/Aims: Multiple meta-analyses and observational studies have reported that alcohol is a risk factor for liver cancer. However, whether there is a safe level of alcohol consumption remains unclear. We performed a systematic review and meta-analysis of the correlation between low-level alcohol consumption and the risk of liver cancer. Methods: Nested case-control studies and cohort studies involving the general population published prior to July 2019 were searched. In total, 28 publications (31 cohorts) with 4,899 incident cases and 10,859 liver cancer-related deaths were included. The pooled odds ratios (ORs) with 95\% confidence intervals (Cls) were calculated. Results: Compared with those with low levels of alcohol consumption, moderate and heavy drinkers ( $\geq 1$ drink/day for females and $\geq 2$ drinks/day for males) had pooled ORs of 1.418 (95\% Cl, 1.192 to 1.687; $\mathrm{p}<0.001)$ for liver cancer incidence and $1.167(95 \% \mathrm{Cl}, 1.056$ to 1.290; $p=0.003$ ) for liver cancer mortality. The pooled OR for liver disease-related mortality for those with more than low levels of alcohol consumption was $3.220(95 \% \mathrm{Cl}, 2.116$ to $4.898 ; p<0.001$ ) and that for all-cause mortality was 1.166 $(95 \% \mathrm{Cl}, 1.065$ to $1.278 ; p=0.001)$. The sensitivity analysis showed that none of the studies had a strong effect on the pooled OR. The Egger test, Begg rank correlation test, and the funnel plot showed no overt indication of publication bias. Conclusions: Continuous consumption of more than a low-level of alcohol ( $\geq 1$ drink/day for females and $\geq 2$ drinks/ day for males) is related to a higher risk of liver cancer. (Gut Liver 2020;14:792-807)
Key Words: Alcohol; Liver neoplasms; Meta-analysis; Risk factors; Systematic review

\section{INTRODUCTION}

According to the World Health Organization, binge drinking is the leading cause of more than 200 diseases and injuries and is associated with premature death and disability; indeed, it is estimated that 3.3 million people worldwide die annually from drinking alcohol. In 1988, the International Agency for Research on Cancer categorized alcohol as a Group 1 human carcinogen. ${ }^{1}$ Additionally, the International Agency for Research on Cancer regards alcohol consumption as a cause of female breast, colorectal, laryngeal, hepatic, esophageal, oral, and pharyngeal cancers. ${ }^{2,3}$ Alcohol consumption is estimated to be responsible for 3.5\% to $4.4 \%$ of cancer deaths annually worldwide..$^{4-6}$

Animal studies have suggested that consumption of small amounts of alcohol, particularly red wine, can prevent cancer and ameliorate cardiovascular disease. ${ }^{7}$ However, clinical trials in humans have not provided corroborative evidence regarding the benefits of red wine. ${ }^{8}$ Few epidemiologic studies have addressed the association between alcohol consumption and cancer risk in humans. A Korean study reported that continuous alcohol consumption, even in small amounts, increases the incidence of esophageal and stomach cancer. ${ }^{9}$

The causes of chronic liver disease, including liver cancer, vary from region to region, but the most frequent are typically chronic viral hepatitis and alcohol. However, the recent development of effective therapeutics for chronic viral hepatitis has

Correspondence to: Jeong Won Jang ${ }^{\mathrm{a}}$ and Joong-Won Park ${ }^{\mathrm{b}}$

${ }^{a}$ Division of Hepatology, Department of Internal Medicine, Seoul St. Mary's Hospital, College of Medicine, The Catholic University of Korea, 222 Banpo-daero, Seocho-gu, Seoul 06591, Korea

Tel: +82-2-2258-6015, Fax: +82-2-3481-4025, E-mail: garden@catholic.ac.kr

${ }^{\mathrm{b}}$ Center for Liver Cancer, National Cancer Center, 323 Ilsan-ro, Ilsandong-gu, Goyang 10408, Korea

Tel: +82-31-920-1605, Fax: +82-31-920-1520, E-mail: jwpark@ncc.re.kr

Received on May 11, 2019. Revised on November 1, 2019. Accepted on November 15, 2019. Published online March 9, 2020.

pISSN 1976-2283 eISSN 2005-1212 https://doi.org/10.5009/gnl19163

Hana Park and Seung Kak Shin contributed equally to this work as first authors.

@) This is an Open Access article distributed under the terms of the Creative Commons Attribution Non-Commercial License (http://creativecommons.org/licenses/by-nc/4.0) which permits unrestricted non-commercial use, distribution, and reproduction in any medium, provided the original work is properly cited. 
increased the importance of alcohol as a cause of liver disease. Alcohol can initiate the development of liver cancer and is related to tumor progression. ${ }^{10-12}$ Regular consumption of 40-60 $\mathrm{g}$ of alcohol is related to a higher risk of liver cancer; this level has been suggested to be lower for women. ${ }^{12,13}$ A recent metaanalysis on the incidence of alcohol-related liver cancer found a significant association between the risk of liver cancer and high-level alcohol consumption, with an excess risk of $66 \%$ for alcohol consumption of $100 \mathrm{~g} /$ day. ${ }^{14}$ Nevertheless, the effect of low-level alcohol consumption ( $<40 \mathrm{~g} /$ day) on the risk of liver cancer was not evaluated and the safe level of alcohol consumption for women was not proposed.

Therefore, we carried out a meta-analysis to determine whether there is a safe level of alcohol consumption in terms of liver cancer risk in men and women. In expressing the amount of alcohol consumption, existing studies used varying units of measurement (number of drinks, ounces, milliliters, or grams consumed every day, week, month, or year); in this study, grams per day (g/day) was used as the standard measure of alcohol intake using the following equivalences: one drink $=0.8 \mathrm{~g} / \mathrm{mL}=28$ $\mathrm{g} /$ ounce $=12.5 \mathrm{~g} /$ drink. According to the definitions in the U.S. Government Dietary Guidelines for Americans (2015 to 2020), light alcohol drinking was defined as less than two drinks/day in males and one drink/day in females. ${ }^{15}$ Using these criteria, we systematically reviewed the existing literature and performed a meta-analysis of the effect of alcohol consumption on the risk of liver cancer.

\section{MATERIALS AND METHODS}

\section{Literature search}

The search for relevant literature was independently performed by two authors (H.P. and S.K.S.), who searched for articles published prior to July 31, 2019 in Embase and PubMed, by using the following search terms: (alcohol OR ethanol) AND (neoplasm OR carcinoma OR cancer) AND (hepatocellular OR liver) AND (prospective OR cohort OR cohort studies [Medical Subject Headings; MeSH Terms]). The titles and abstracts of all retrieved studies were scanned to exclude all irrelevant studies, and inconsistencies were resolved by review of the full text and discussion. The full texts of the remaining papers were examined to assess their eligibility. We also examined the reference lists of all retrieved articles. This meta-analysis was performed according to the Preferred Reporting Items of the Systematic Reviews and Meta-Analyses statement. ${ }^{16}$

\section{Inclusion and exclusion criteria}

The inclusion criteria were as follows: (1) original research articles of nested case-control or cohort studies (letters, reviews, and abstracts were excluded); (2) articles reporting the incidence and mortality of primary liver cancer or hepatocellular carcinoma as odds ratios (ORs), hazard ratios, or relative risks (RRs) (at least two levels of alcohol consumption vs nondrinkers and/ or occasional drinkers); and (3) articles using standard errors or confidence intervals (CIs) of the risk estimates or those that provided sufficient data to calculate them. The exclusion criteria

2,067 Papers identified through literature search:
using the following search string in PubMed: and Embase
(alcohol OR ethanol) AND (liver OR hepatocellular) AND
(cancer OR neoplasm OR carcinoma) AND (cohort OR prospective)

\begin{tabular}{|c|c|}
\hline & $\begin{array}{l}\text { Excluded: } \\
98 \text { Not human data } \\
167 \text { Written in non-English } \\
\text { 1,420 Not relevant papers } \\
\text { (title and/or abstract were not relevant } \\
\text { for the end point of the study) }\end{array}$ \\
\hline \multicolumn{2}{|c|}{$\begin{array}{l}382 \text { Full-text papers considered for the inclusion } \\
\text { (the bibliographies of relevant articles added, } n=10 \text { ) }\end{array}$} \\
\hline & $\begin{array}{l}\text { Excluded: } \\
135 \text { Not relevant } \\
52 \text { Studies with no available data for } \\
\text { outcome measures (RR/OR/HR) } \\
120 \text { Other study designs (not cohort or } \\
\text { nested case-control) } \\
7 \text { Shared an identical population } \\
32 \text { Insufficient data } \\
8 \text { Review or meta-analysis }\end{array}$ \\
\hline
\end{tabular}

28 Papers included in the meta-analysis
Fig. 1. Flowchart of the literature search and inclusion criteria of the meta-analysis. $\mathrm{RR} / \mathrm{OR} / \mathrm{HR}$, relative risk/odds ratio/ hazard ratio. 


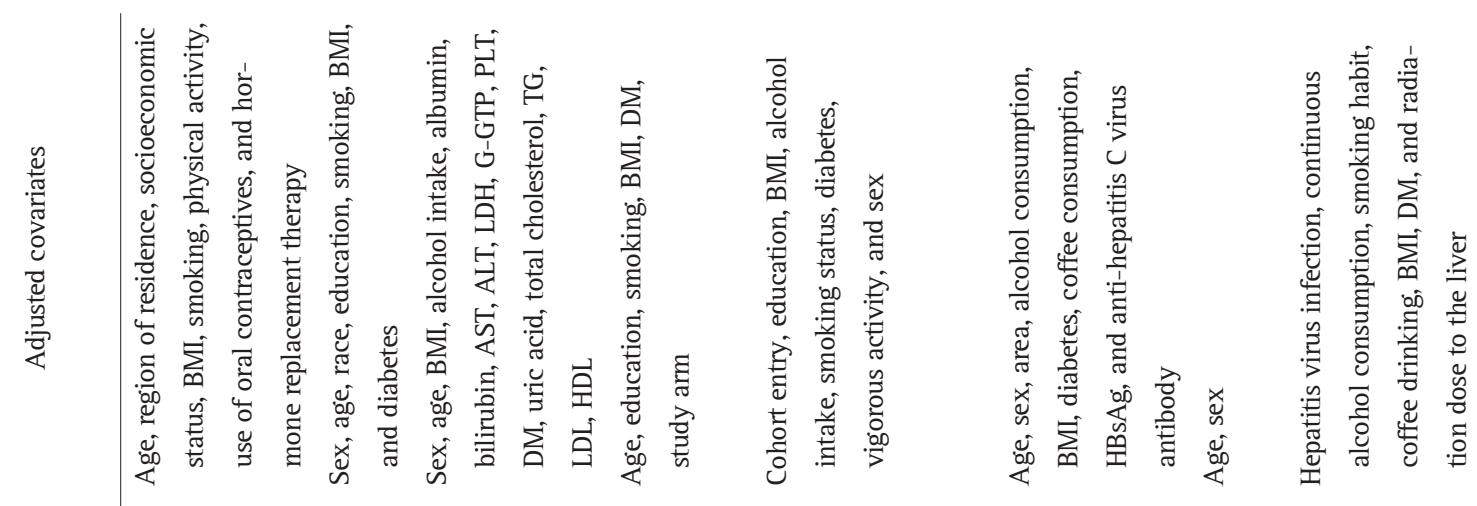

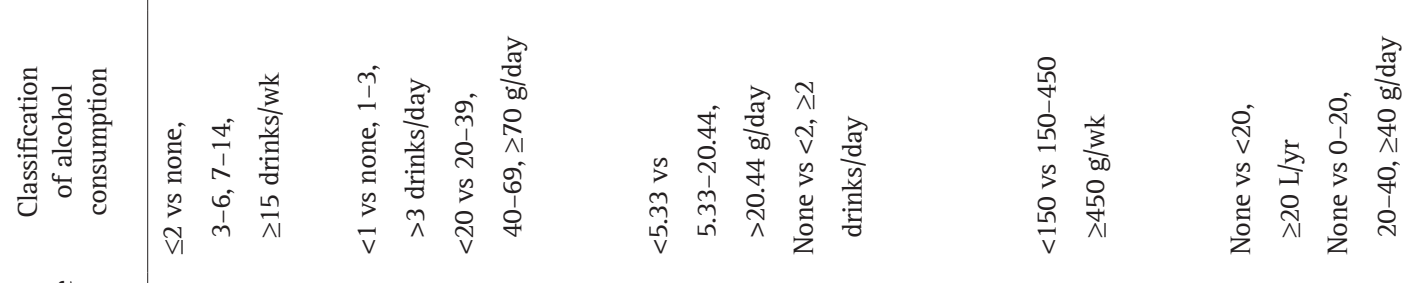
嵌

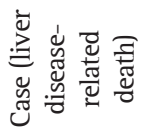

$\stackrel{\llcorner}{\infty}$

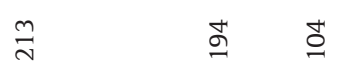

号导总宽

苋芭芯芯

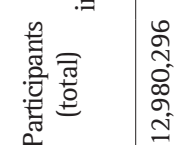

音

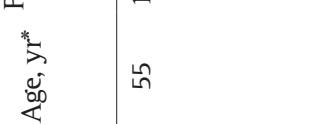

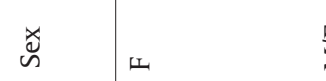

密高

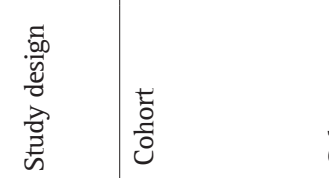

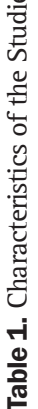

言 光

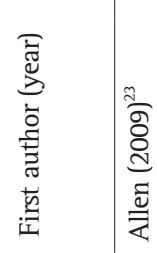

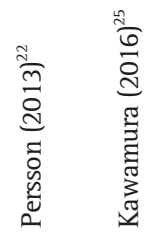

8
1
1
ind

$\stackrel{Ð}{\circ}$

苛

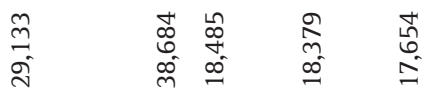

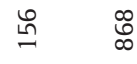

\begin{tabular}{ll}
\multirow{1}{1}{} & $\stackrel{0}{1}$ \\
0 & 9
\end{tabular}

崖崖

$\Sigma \quad \frac{\omega}{\Sigma} \stackrel{\frac{\omega}{\omega}}{\Sigma}$

崖紧

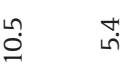

- $\quad \begin{aligned} & 0 \\ & \dot{9}\end{aligned}$

$\sim \quad \pi$

형

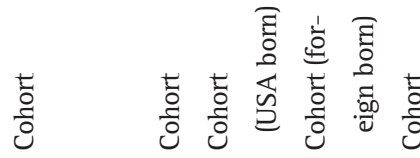

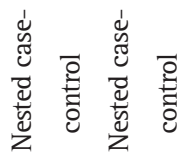

芯慗

褐

๘ุ'

ฐ్ฐี

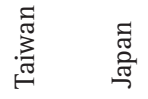

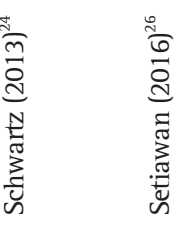

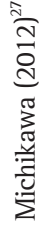

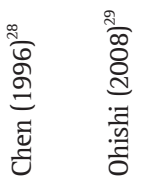




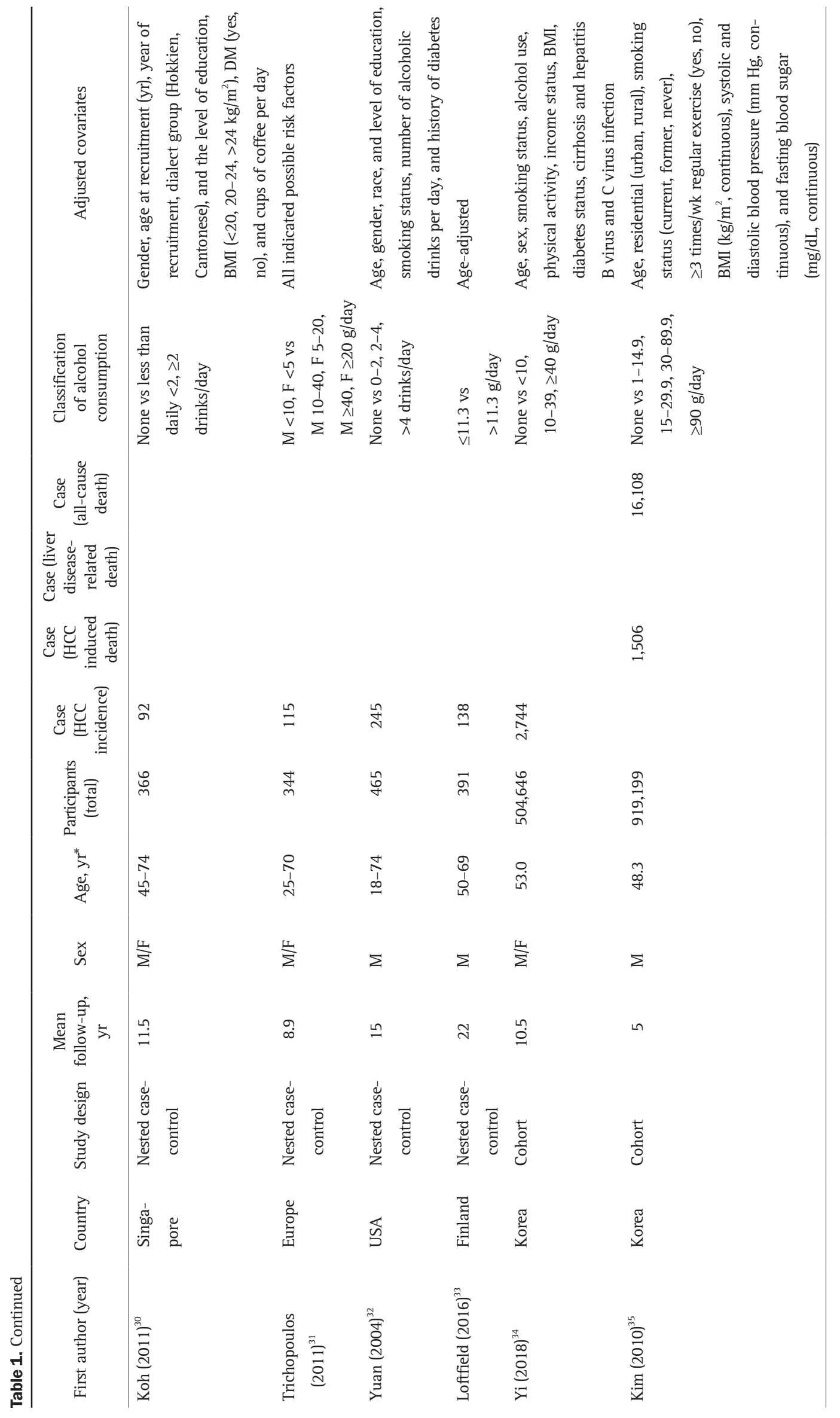



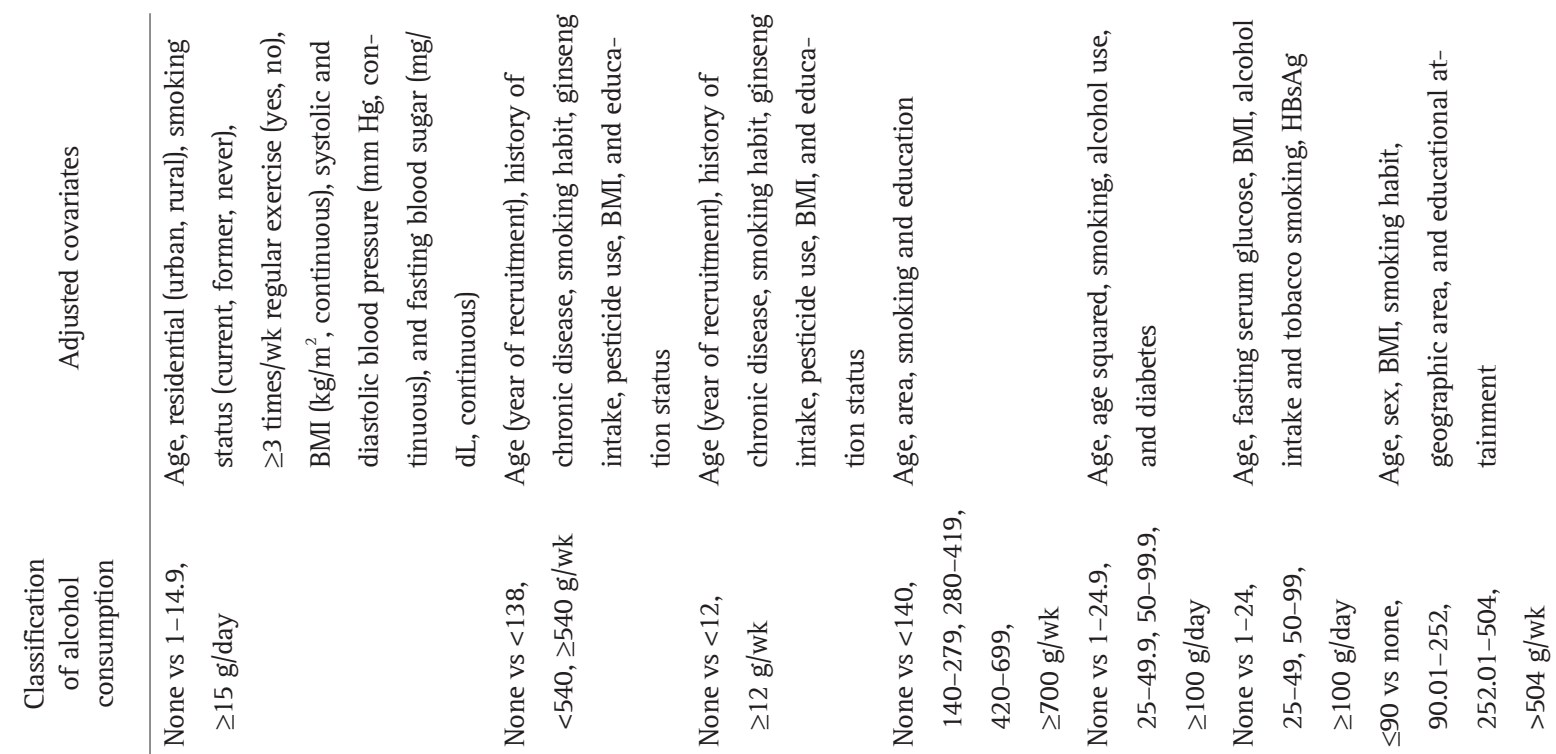

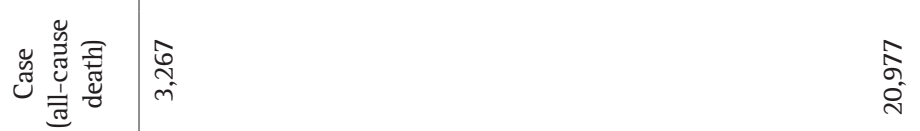

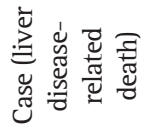

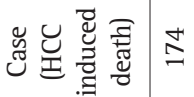

$\stackrel{m}{m}$

กิ

$\stackrel{n}{\Rightarrow} \quad$ ले $\quad$ \%े

离芯芯

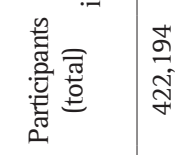

:

\&
ते

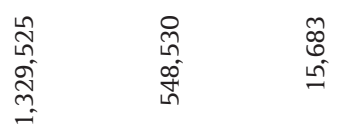

\begin{tabular}{l|l}
${ }_{5}^{*}$ & F \\
$\stackrel{8}{8}$ &
\end{tabular}

?్ֶరి

के

a

$\begin{array}{ll}\stackrel{0}{0} & 0 \\ 0 & 0 \\ 0 & 0\end{array}$

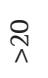

$\stackrel{\varpi}{\varpi}$

$\Sigma$

山

崖雀

离产 5

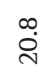

$\stackrel{\infty}{\stackrel{i}{0}}$

$\stackrel{-1}{2}$

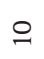

n.

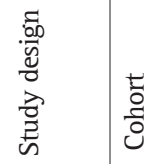

홍

憘

㖥

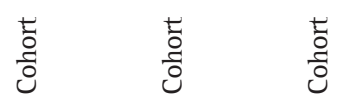

莺

ฐั๊

荧

๕ี

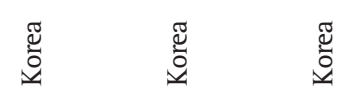

$\underset{\substack{0 \\ \stackrel{0}{0}}}{\stackrel{0}{0}}$

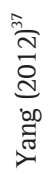

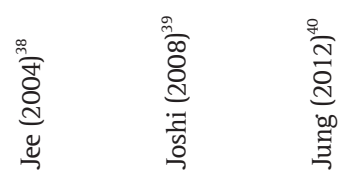




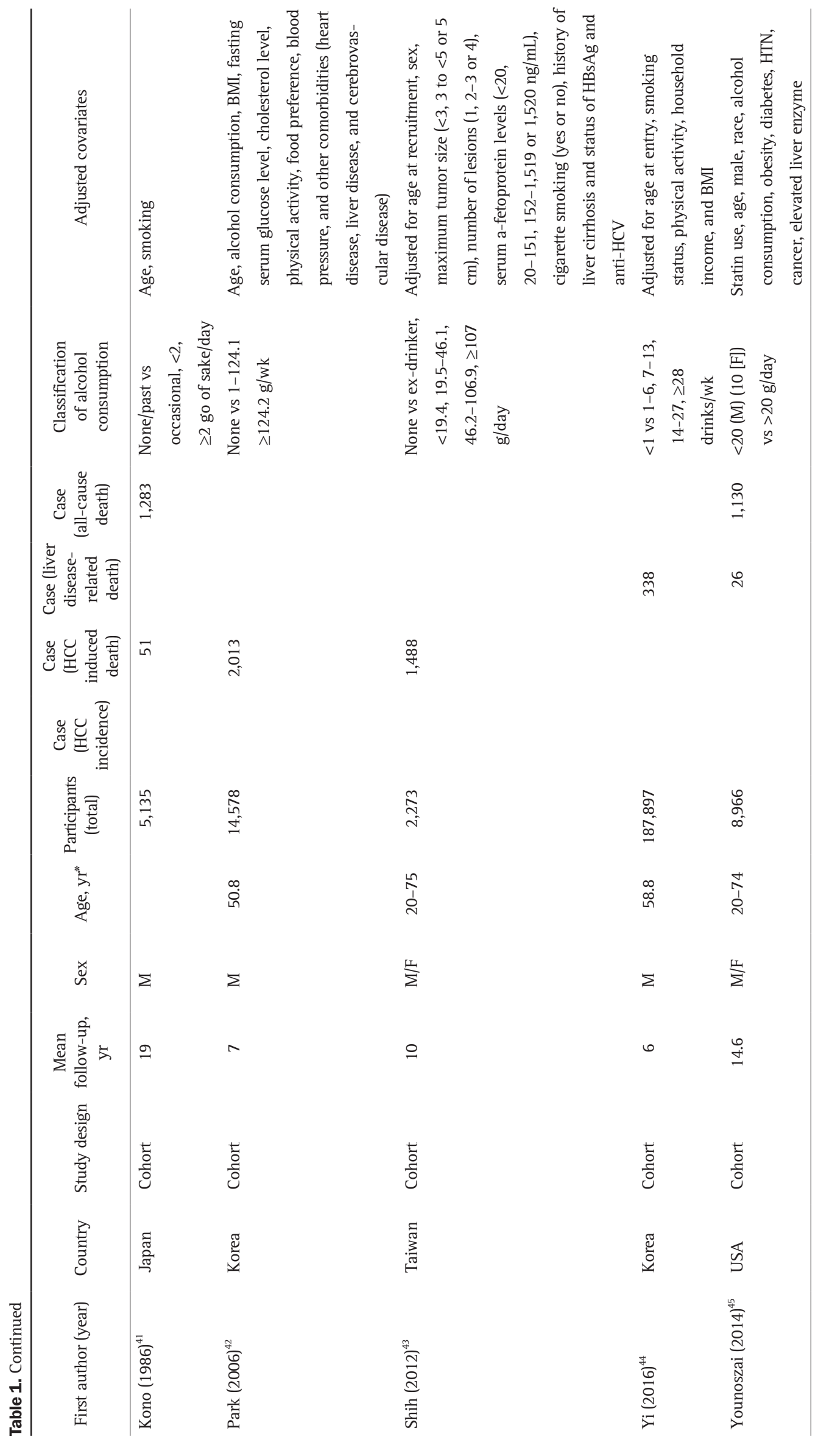




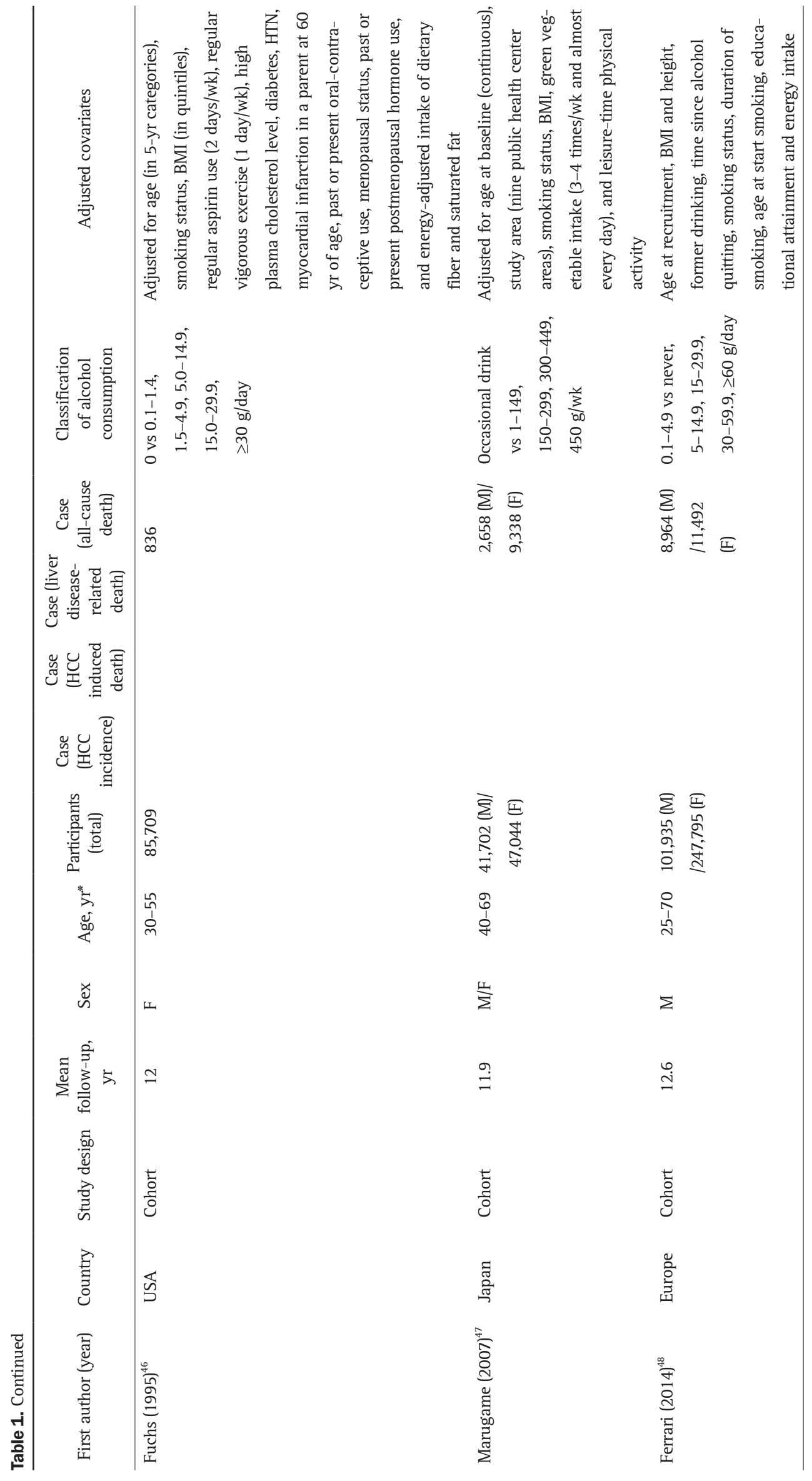




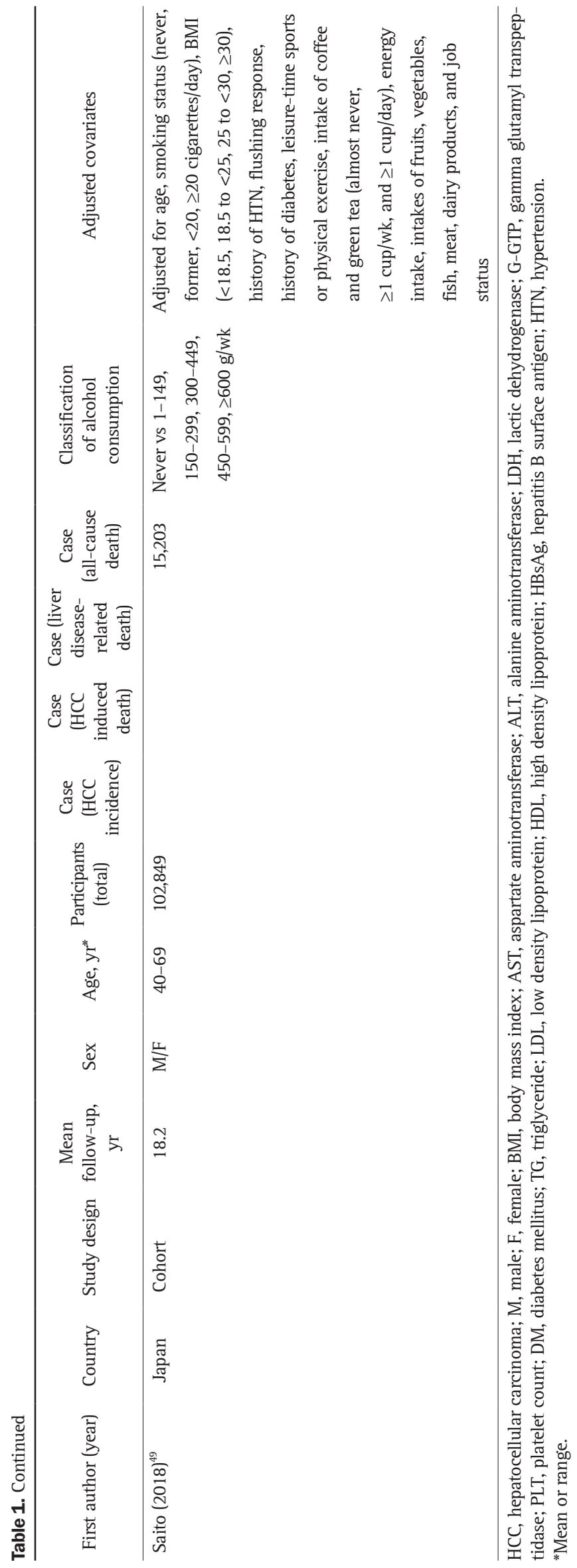



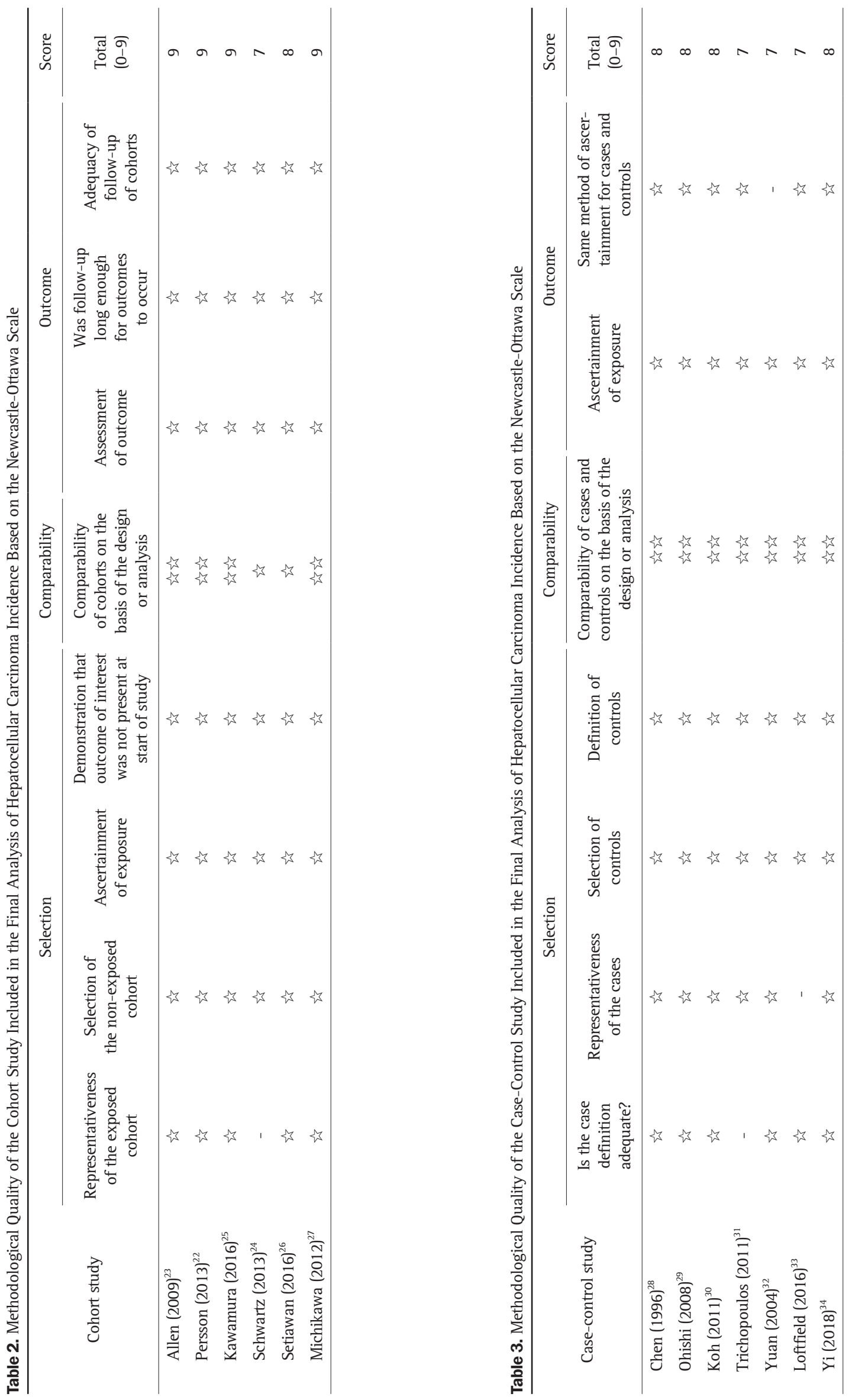
were: (1) non-English language articles; (2) non-human studies; and (3) no classification of alcohol consumption. When multiple studies involved the same population, the most recent article was included.

\section{Data extraction and quality assessment}

Two independent authors (H.P. and S.K.S.) extracted data from the included studies. The following details were retrieved from each study: (1) first author's name and the year of publication, (2) country, (3) design, (4) follow-up period, (5) subjects' gender distribution, (6) subjects' mean age, (7) number of subjects, (8) classification of alcohol consumption, (9) effect size (OR, harzard ratio, or relative risk and 95\% $\mathrm{CI}$ ), and (10) confounders adjusted for. The Newcastle-Ottawa Scale (NOS) was used to estimate the quality of the studies. ${ }^{17}$ The NOS score ranges from 0 to 9 and is defined as the sum of the scores of the following three subscales: selection of studies, comparability, and outcome. A higher score indicates greater methodological quality. Studies with NOS scores $\geq 7$ were noted as high quality.

\section{Statistical analysis}

We used the fixed- and random-effects models to estimate the pooled ORs with 95\% CIs. Sufficiently homogenous groups of studies were analyzed with the fixed-effects model, and more heterogeneous groups of studies were analyzed with the random-effects model. ${ }^{18}$ We used Forest plots to identify the heterogeneity among studies, which was quantified using the $\mathrm{I}^{2}$ index, which represents the percentage of the total variability in a set of effect sizes rising from the true heterogeneity among studies. ${ }^{19}$ To evaluate the stability of the meta-analysis, we carried out a sensitivity analysis. The pooled OR of the remaining studies was computed by excluding one study at a time and compared with that of the fixed-effects model or random-effects model. The funnel plot or Egger regression test was utilized to evaluate the publications. ${ }^{20}$ When the articles provided ORs by using a different reference category, the ORs were newly calculated by dividing each OR by the OR for non-drinking; CIs were calculated by employing the standard errors of the crude OR estimates that were penalized by a factor of 1.5..$^{21,22}$

Comprehensive Meta-Analysis version 2.0 (Biostat, Inc., Englewood, NJ, USA) was used for carrying out all statistical analyses. p-values smaller than 0.05 (two-sided) were considered statistically significant.

\section{RESULTS}

A total of 2,067 articles were initially retrieved from PubMed and Embase. After applying the exclusion criteria, the full texts of 382 potentially relevant studies were reviewed. Of these, 28 were finally included for meta-analysis (Fig. 1): $:^{22-49} 22$ were cohort studies and six nested case-control studies; 18 studies were from Asia, five were from the United States, and the other five were from Europe.

Table 1 shows the characteristics of the included studies. In total, 28 publications (31 cohorts) were included. A total of 4,899 incident cases and 10,859 deaths from liver cancer were included in the articles as a whole. A total of 1,669 deaths from liver disease and 91,256 all-cause deaths were also included.

Tables 2 and 3 shows the methodological qualities of the cohort and nested case-control studies. The average score was 7.5 for case-control studies and 8.5 for cohort studies (range, 7-9). All included studies were of high quality (NOS score $\geq 7$ ). Quality assessment regarding alcohol and mortality from liver cancer, all-cause, and liver diseases was also performed (Supplement Tables 1-3).

Fig. 2A shows the Forest plot regarding the relationship between the incidence of liver cancer and more than light drinking versus never or light drinking. The pooled OR was 1.418 (95\% CI, 1.192 to $1.687 ; \mathrm{p}<0.001 ; \mathrm{I}^{2}=60.5 \%$ ) based on 13 studies. The sensitivity analysis showed that no single study had significantly affected the overall results (Fig. 2B). The funnel plot in the analysis of liver cancer incidence and more than light drinking versus never or light drinking showed evidence of publication bias in Egger test $(\mathrm{p}=0.010)$, but not Begg rank correlation test $(\mathrm{p}=0.502)$ (Fig. 2C). After using the trim-and-fill analysis to correct for this bias, a pooled OR of 1.141 (95\% CI, 0.958 to 1.259) was calculated using the random-effects model.

The pooled OR for mortality from liver cancer for more than light drinking versus never or light drinking was 1.167 (95\% CI, 1.056 to $1.290 ; \mathrm{p}=0.003 ; \mathrm{I}^{2}=61.1 \%$ ) based on nine studies ( 11 cohorts) (Fig. 3A). The sensitivity analysis demonstrated that no single study conferred a significant impact on the pooled OR (Fig. 3B). The funnel plot, Egger ( $\mathrm{p}=0.409$ ) and Begg rank correlation test $(p=0.640)$ indicated no overt indication of publication bias in the analysis of liver cancer mortality (Fig. 3C).

The pooled OR of liver disease-related mortality for more than light drinking versus never or light drinking was 3.220 (95\% CI, 2.116 to $4.898 ; \mathrm{p}<0.001 ; \mathrm{I}^{2}=66.7 \%$ ) based on five studies (six cohorts) (Fig. 4A). The pooled OR for all-cause mortality for more than light drinking versus never or light drinking was 1.166 (95\% CI, 1.065 to $1.278 ; p=0.001 ; I^{2}=48.9 \%$ ) based on eight studies (10 cohorts) (Fig. 5A). In both analyses, the sensitivity analysis demonstrated that no single study conferred a significant impact on the pooled OR (Figs. 4B, 5B), and the funnel plot, Egger ( $p=0.603$ and $p=0.466$, respectively) and Begg rank correlation test $(\mathrm{p}=0.133$ and $\mathrm{p}=1.000$, respectively) indicated no overt indication of publication bias (Figs. 4C, 5C).

\section{DISCUSSION}

We investigated the relationship between liver cancer and alcohol consumption. Most previous studies of the incidence and mortality of liver cancer have been conducted on people who drink more than 40-69 g of alcohol per day for both genders. In 
A

Study name

Allen (2009)

Persson (2013)

Kawamura (2016)

Schwartz (2013)

Setiawan (2016)

Michikawa (2012)

Chen (1996)

Ohishi (2008)

Koh (2011)

Trichopoulos (2011)

Yuan (2004)

Loftfield (2016)

Yi (2018)
Statistics for each study

Odds

ratio limit limit

$\begin{array}{lll}1.140 & 0.982 & 1.323\end{array}$

3.730

1.520

1.490

1.500

5.800

2.120

2.240

0.900

2.130

1.360

1.080

1.418
0.701

0.879

1.060

0.889

0.421

1.199

0.979

1.466

0.251

0.949

0.885

1.041

1.192
2.676

15.820

2.180

2.497

5.339

28.067

4.593

3.423

3.225

4.783

2.089

1.121

1.687

$$
\begin{array}{r}
\text { Z-value } \\
1.725 \\
0.922 \\
1.786 \\
2.276 \\
1.513 \\
0.626 \\
2.185 \\
1.905 \\
3.727 \\
-0.162 \\
1.832 \\
1.404 \\
4.071 \\
3.944
\end{array}
$$

\section{Odds ratio and $95 \% \mathrm{Cl}$}

p-value

0.085

0.074

0.023

0.130

0.531

0.029

0.057

0.000

0.871

0.067

0.160

0.000

0.000

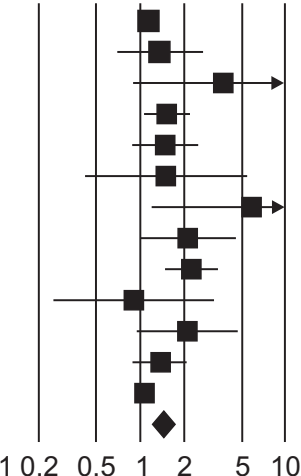

Favours A Favours B

B

Study name

Allen (2009)
Persson (2013)
Kawamura (2016)
Schwartz (2013)
Setiawan (2016)
Michikawa (2012)
Chen (1996)
Ohishi (2008)
Koh (2011)
Trichopoulos (2011)
Yuan (2004)
Loftfield (2016)
Yi (2018)

Statistics with study removed

Point

1.580

1.427

1.391

1.404

1.416

1.422

1.379

1.387

1.289

1.436

1.389

1.433

1.558

1.418

\section{Lower Upper}

limit limit

1.230

1.190

1.174

1.168

1.180

1.190

1.169

1.166

1.111

1.201

1.168

1.189

1.261

1.192
2.028

1.712

1.649

1.687

1.699

1.698

1.626

1.649

1.495

1.715

1.652

1.728

1.926

1.687
Z-value

3.587

3.839

3.804

3.617

3.737

3.880

3.810

3.699

3.344

3.979

3.714

3.773

4.101

3.944
Odds ratio $(95 \% \mathrm{Cl})$ with study removed

$\mathrm{p}$-value

0.000

0.000

0.000

0.000

0.000

0.000

0.000

0.000

0.001

0.000

0.000

0.000

0.000

0.000
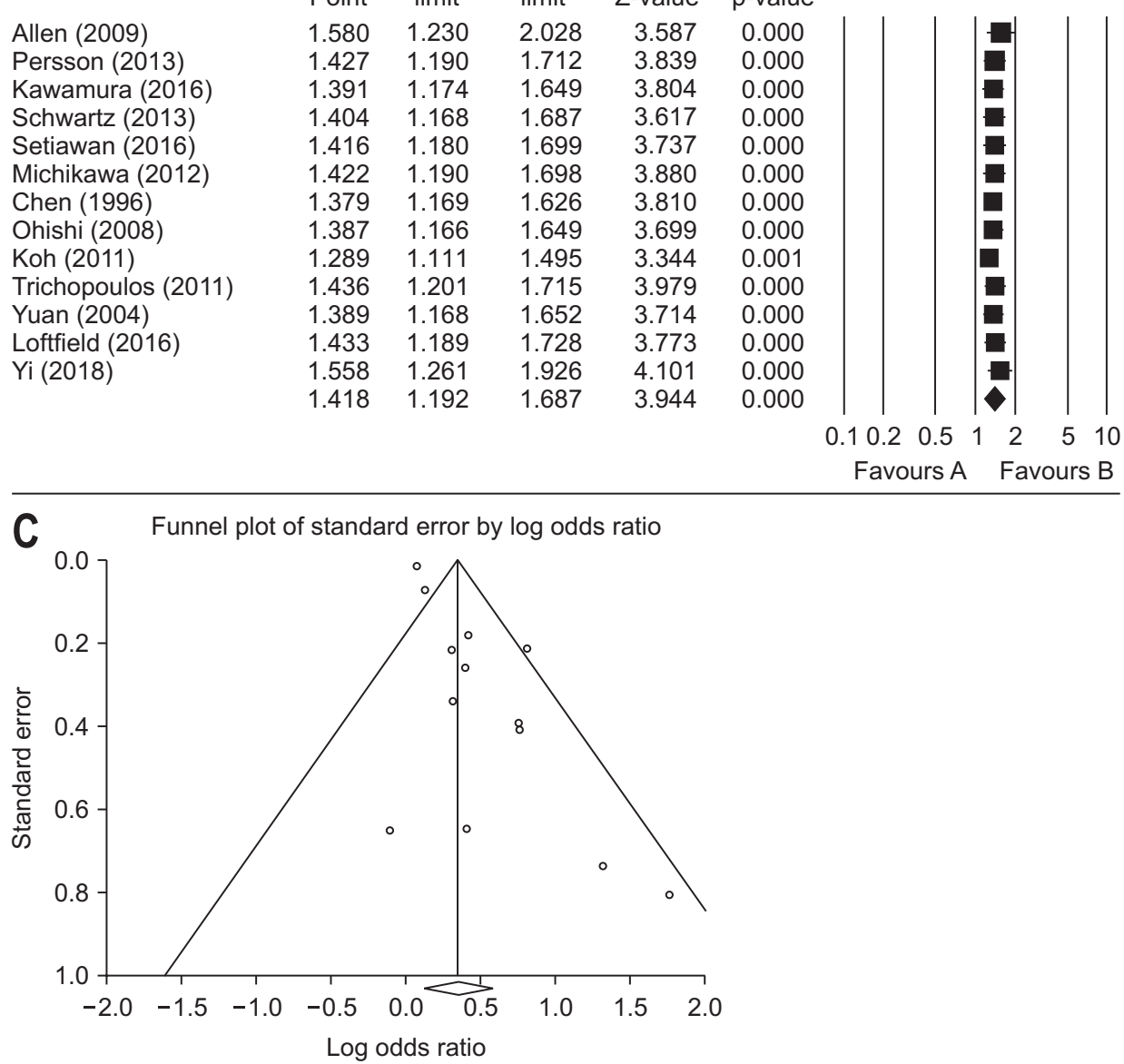

Fig. 2. Meta-analysis of studies examining the relationship between the incidence of liver cancer and moderate/heavy light alcohol consumption versus never or a low level of alcohol consumption. (A) Forest plot; (B) sensitivity test; (C) funnel plot.

$\mathrm{CI}$, confidence interval.

this study, however, light alcohol consumption standards of less than two drinks/day for males and one drink/day for females were used for analysis. We also assessed the overall relationship between alcohol and liver disease based not only on the incidence of liver cancer and the associated mortality rates but also on the mortality rate of liver disease and the all-cause mortality rate.

More than light alcohol drinkers had a 42\% increased risk of liver cancer incidence and 17\% increased risk of liver cancer death compared to those who drink less alcohol. The liver-related mortality rate was 3.2-fold higher in more than moderate drinkers compared to those who drink less alcohol, demon- 
A

Study name

Kim (2010) male

Kim (2010)_female

Yi (2010)_male

Yi (2010) female

Yang (2012)

Jee (2004)

Joshi (2008)

Jung (2012)

Kono (1986)

Park (2006)

Shih (2012)

\begin{tabular}{cccr} 
& \multicolumn{3}{c}{ Statistics for each study } \\
$\begin{array}{c}\text { Odds } \\
\text { ratio }\end{array}$ & $\begin{array}{c}\text { Lower } \\
\text { limit }\end{array}$ & $\begin{array}{c}\text { Upper } \\
\text { limit }\end{array}$ & Z-value \\
1.080 & 0.935 & 1.247 & 1.049 \\
1.800 & 0.904 & 3.585 & 1.672 \\
0.860 & 0.449 & 1.647 & -0.455 \\
1.060 & 0.131 & 8.556 & 0.055 \\
1.180 & 1.071 & 1.301 & 3.332 \\
1.110 & 0.928 & 1.327 & 1.143 \\
0.920 & 0.796 & 1.064 & -1.124 \\
2.410 & 1.398 & 4.154 & 3.166 \\
2.700 & 1.035 & 7.041 & 2.031 \\
1.250 & 1.109 & 1.409 & 3.656 \\
1.220 & 1.097 & 1.357 & 3.674 \\
1.167 & 1.056 & 1.290 & 3.022
\end{tabular}

Odds ratio and $95 \% \mathrm{Cl}$

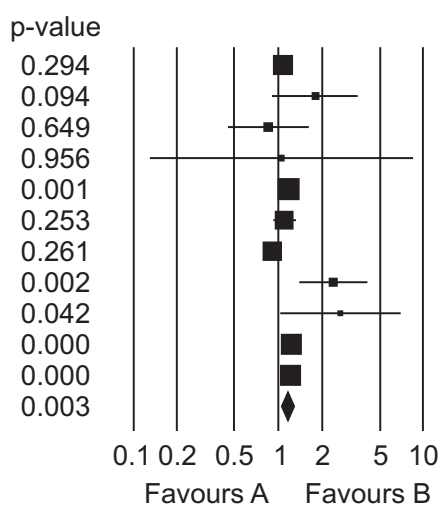

Favours A Favours B

\section{B}

Study name

Kim (2010)_male
Kim (2010)_female
Yi (2010)_male
Yi (2010)_female
Yang (2012)
Jee (2004)
Joshi (2008)
Jung (2012)
Kono (1986)
Park (2006)
Shih (2012)

\begin{tabular}{cccc} 
& \multicolumn{3}{c}{ Statistics with study removed } \\
\cline { 2 - 4 } Power & Upper & \\
Point & limit & limit & Z-value \\
1.186 & 1.058 & 1.331 & 2.914 \\
1.157 & 1.047 & 1.278 & 2.853 \\
1.175 & 1.061 & 1.301 & 3.104 \\
1.168 & 1.055 & 1.294 & 2.978 \\
1.175 & 1.036 & 1.332 & 2.506 \\
1.179 & 1.053 & 1.320 & 2.849 \\
1.202 & 1.106 & 1.307 & 4.315 \\
1.141 & 1.046 & 1.244 & 2.974 \\
1.155 & 1.049 & 1.272 & 2.942 \\
1.156 & 1.029 & 1.299 & 2.445 \\
1.164 & 1.031 & 1.314 & 2.457 \\
1.167 & 1.056 & 1.290 & 3.022 \\
& & &
\end{tabular}

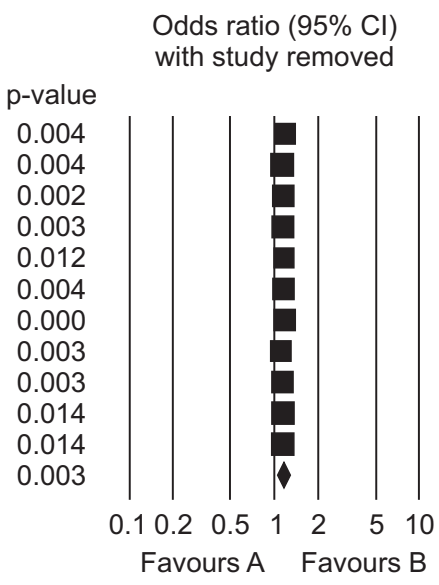

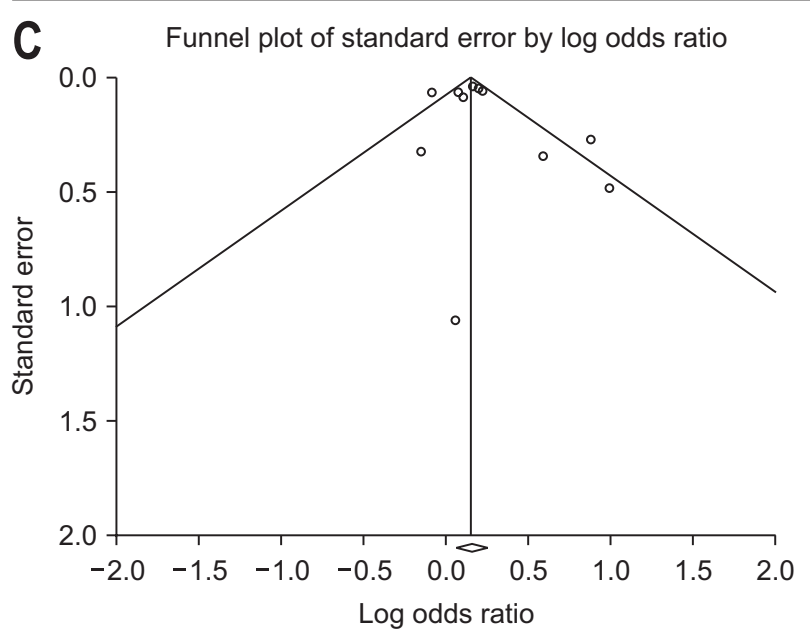

strating that consumption of even one or two alcoholic drinks daily can have an adverse effect on health. The risk of all-cause mortality in more than light drinkers was 16\% higher compared to those who drink less alcohol. A slight decrease in the risk of all-cause mortality compared to that of liver-related mortality can be assumed that cardiovascular diseases reported to be able to protect with a small amount of drinking was included in allcause mortality.

Fig. 3. Meta-analysis of studies examining the relationship between mortality from liver cancer and moderate/heavy alcohol consumption versus never or a low level of alcohol consumption. (A) Forest plot; (B) sensitivity test; (C) funnel plot.

CI, confidence interval.
Studies in animals have shown that alcohol consumption in small amounts, especially red wine, can prevent cancer and ameliorate cardiovascular disease. Indeed, some components of red wine, such as resveratrol, have anticancer activity. ${ }^{7}$ Resveratrol is also present in peanuts, grapes, raspberries, and some other plants. Resveratrol is a polyphenol antioxidant produced by various plants to defend against fungi, stress, injury, infection, and excess sunlight; moreover, its effect on cancer and 
A

Study name

Setiawan (2016)_US born
Setiawan (2016)_Foreign born
Persson (2013)
Schwartz (2013)_male
Yi (2016)_male
Younoszai (2014)

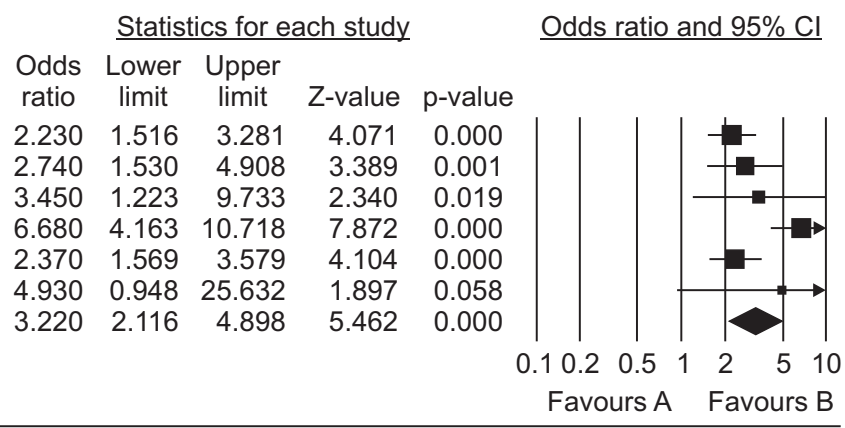

B Study name

Setiawan (2016)_US born
Setiawan (2016)_Foreign born
Persson (2013)
Schwartz (2013)_male
Yi (2016)_male
Younoszai (2014)

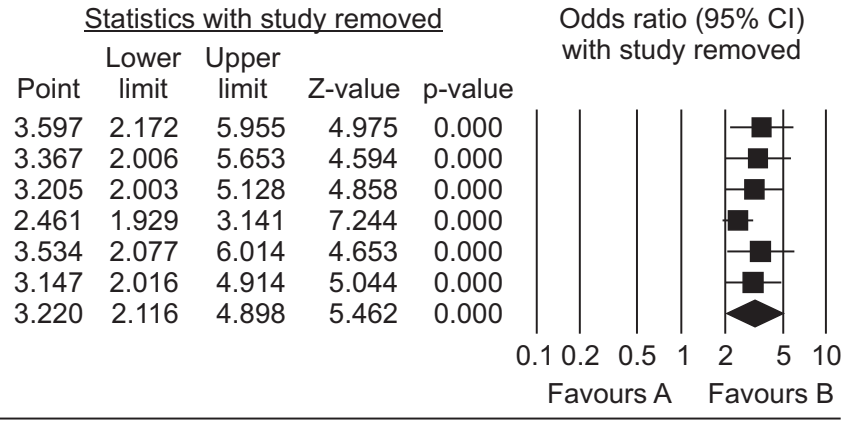

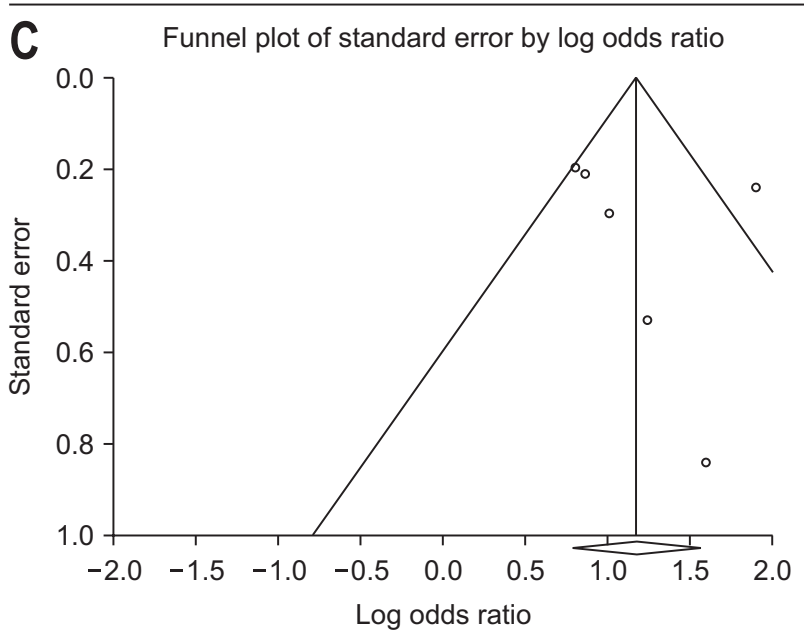

Fig. 4. Meta-analysis of studies examining the relationship between liver disease-related mortality and moderate/heavy alcohol consumption versus never or a low level of alcohol consumption. (A) Forest plot; (B) sensitivity test; (C) funnel plot.

CI, confidence interval. heart disease is under investigation. However, clinical trials have shown that resveratrol is not effective for preventing or treating cancer. ${ }^{8}$ Alcohol was categorized as a human liver carcinogen by the International Agency for Research on Cancer in 1988. ${ }^{1}$ Alcohol can initiate the development of liver cancer and is significantly associated with tumor progression. The underlying mechanisms of the promotion by alcohol and its metabolite, acetaldehyde, of liver carcinogenesis include: ${ }^{10-12}$ (1) increased oxidative stress, which damages DNA and hampers its repair; (2) induction of liver injury, promoting fibrogenesis and cirrhosis (most alcohol-related liver cancers develop from liver cirrhosis); (3) interactions with other environmental carcinogens, such as tobacco smoke; (4) interruption of one-carbon metabolism, leading to impaired DNA methylation and altered gene expression.
Previous meta-analyses have reported that regular consumption of 40-60 $\mathrm{g}$ of alcohol is related to a higher risk of liver cancer and proposed a lower level of safe alcohol consumption for women. ${ }^{12,13}$ Turati et al. ${ }^{14}$ systematically reviewed and metaanalyzed the relation between alcohol intake and the incidence of liver cancer and death by including 16 articles (19 cohorts) that comprised a total of 4,445 incident cases and 5,550 liver cancer-related deaths; as a results, the authors found a significant linear association between alcohol consumption and liver cancer risk (excess risk $46 \%$ for $50 \mathrm{~g}$ of alcohol per day and $66 \%$ for $100 \mathrm{~g}$ per day). Although the authors reported a doserisk association between alcohol consumption and liver cancer risk, they did not evaluate the risk of consumption of smaller amounts of alcohol and did not analyze gender standards separately. Additionally, the risk of liver cancer comprised both the 
A

Study name

$\operatorname{Kim}$ (2010)_male

Kim (2010)female

Jung (2012)

Kono (1986)

Fuchs (1995)_female

Marugame (2007)_male

Marugame (2007)_female

Ferrari (2014)_male

Saito (2017)

Younoszai (2014)
Statistics for each study

$\begin{array}{lll}\text { Odds } & \text { Lower } & \text { Upper } \\ \text { ratio limit limit }\end{array}$

$\begin{array}{lll}1.070 & 0.864 & 1.326\end{array}$

$\begin{array}{lll}1.270 & 1.069 & 1.509\end{array}$

$\begin{array}{lll}1.350 & 1.114 & 1.636\end{array}$

$\begin{array}{lll}1.280 & 1.074 & 1.526\end{array}$

$0.970 \quad 0.807$

$\begin{array}{ll}1.230 & 0.959\end{array}$

$1.290 \quad 0.961$

$\begin{array}{ll}1.200 & 0.949\end{array}$

$0.910 \quad 0.763$

$\begin{array}{ll}1.270 & 1.017\end{array}$

1.166

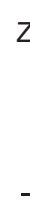

\section{Odds ratio and $95 \% \mathrm{Cl}$}

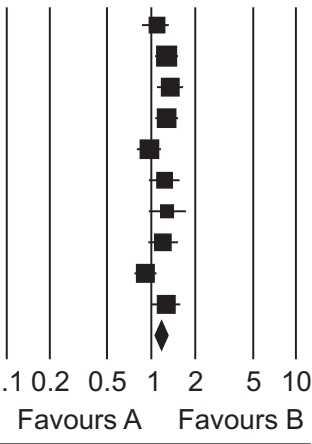

\section{B}

Study name

Kim (2010)_male
Kim (2010)_female
Jung (2012)
Kono (1986)
Fuchs (1995)_female
Marugame (2007)_male
Marugame (2007)_female
Ferrari (2014)_male
Saito (2017)
Younoszai (2014)

\begin{tabular}{ccc} 
& \multicolumn{3}{c}{ Statistics with stud } \\
Point & $\begin{array}{c}\text { Lower } \\
\text { limit }\end{array}$ & $\begin{array}{c}\text { Upper } \\
\text { limit }\end{array}$ \\
1.178 & 1.066 & 1.301 \\
1.154 & 1.043 & 1.276 \\
1.145 & 1.042 & 1.259 \\
1.153 & 1.043 & 1.273 \\
1.193 & 1.090 & 1.306 \\
1.161 & 1.052 & 1.283 \\
1.158 & 1.051 & 1.276 \\
1.164 & 1.053 & 1.287 \\
1.205 & 1.119 & 1.297 \\
1.157 & 1.048 & 1.277 \\
1.166 & 1.065 & 1.278
\end{tabular}

y removed
Z-value
3.217
2.789
2.816
2.791
3.841
2.953
2.969
2.966
4.927
2.879
3.311

p-value
0.001
0.005
0.005
0.005
0.000
0.003
0.003
0.003
0.000
0.004
0.001

Odds ratio $(95 \% \mathrm{Cl})$ with study removed

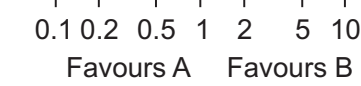

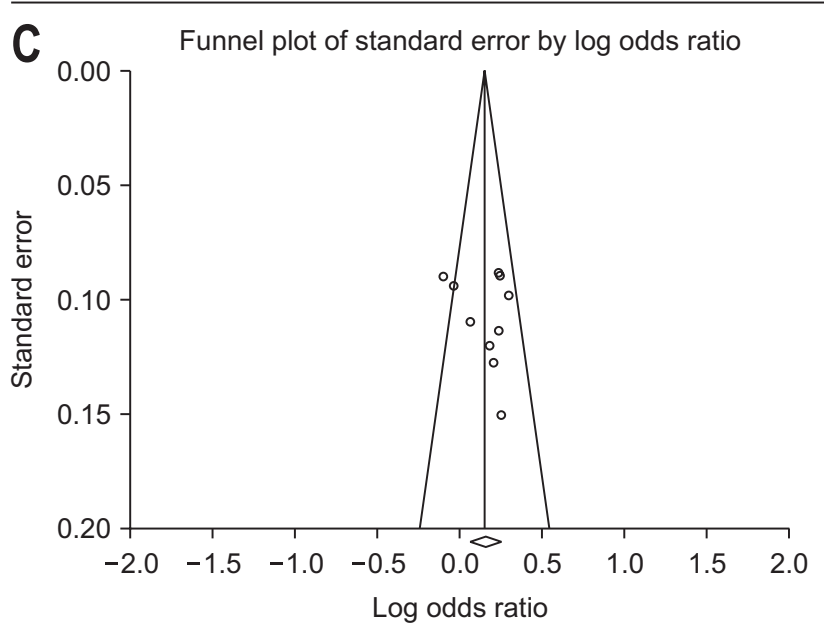

incidence and mortality rates of liver cancer; these were not evaluated separately. Another recent meta-analysis demonstrated that alcohol consumption is associated with a higher risk of liver cancer in a dose-dependent manner (8\% for $12 \mathrm{~g}$ alcohol per day, 54\% for $50 \mathrm{~g}$ per day, and 3.2-fold for $100 \mathrm{~g}$ per day). ${ }^{50}$ Moreover, synergistic effects with other risk factors such as hepatitis and diabetes were detected. However, the enrolled studies showed significant heterogeneity as well as publication bias.

This study had the following limitations. First, we may have
Fig. 5. Meta-analysis of studies examining the relationship between all-cause mortality and moderate/ heavy alcohol consumption versus never or a low level of alcohol consumption. (A) Forest plot; (B) sensitivity test; (C) funnel plot.

CI, confidence interval. omitted the liver cancer data included in the results of our study with all kinds of cancer since we found a paper exclusively for the event in livers. Secondly, there was some heterogeneity among the articles, as with most meta-analyses. However, we overcame this limitation by applying random-effects and fixedeffects models according to heterogeneity. Sensitivity analyses supported the robustness of our study results. Moreover, Egger tests for funnel plot asymmetry and the funnel plot did not indicate the presence of major publication bias.

In conclusion, this meta-analysis supports previous reports 
of the association between alcohol consumption and the risk of liver cancer. Furthermore, our research shows that continuous consumption of even a small amount of alcohol is related to liver cancer risks. Based on this analysis, more than light alcohol consumption should be considered harmful as it not only increases the incidence of liver cancer but also increases liver disease and overall mortality.

\section{CONFLICTS OF INTEREST}

No potential conflict of interest relevant to this article was reported.

\section{ACKNOWLEDGEMENTS}

This study project was supported by The Korean Liver Cancer Association.

We thank Professor Hyeon Woo Yim (Catholic University of Korea), Hyunsuk Jeong (Catholic University of Korea), KwangPil Ko (Gachon University College of Medicine) and Seokyung Hahn (Seoul National University College of Medicine) for their helpful statistical assistance. The statistical consultation was supported by Catholic Research Coordinating Center of the Korea Health 21 R\&D Project (A070001), Ministry of Health \& Welfare, and Republic of Korea.

\section{AUTHOR CONTRIBUTIONS}

Study concept and design: H.P., S.K.S., I.J., D.S.S., J.W.J. Data acquisition; data analysis and interpretation: H.P., S.K.S., J.W.J. Drafting of the manuscript; critical revision of the manuscript for important intellectual content: H.P., S.K.S. Statistical analysis: H.P., S.K.S. Study supervision: J.W.J., J.W.P.

\section{ORCID}

Hana Park

Seung Kak Shin

https://orcid.org/0000-0001-8449-034X

Ijin Joo

Do Seon Song

Jeong Won Jang

Joong-Won Park

https://orcid.org/0000-0002-5120-5300

https://orcid.org/0000-0002-1341-4072

https://orcid.org/0000-0002-8278-4878

https://orcid.org/0000-0003-3255-8474

https://orcid.org/0000-0001-9972-0494

\section{REFERENCES}

1. Alcohol drinking. IARC Working Group, Lyon, 13-20 October 1987. IARC Monogr Eval Carcinog Risks Hum 1988;44:1-378.

2. IARC Working Group on the Evaluation of Carcinogenic Risks to Humans. Alcohol consumption and ethyl carbamate. IARC Monogr Eval Carcinog Risks Hum 2010;96:3-1383.

3. Cogliano VJ, Baan R, Straif K, et al. Preventable exposures associated with human cancers. J Natl Cancer Inst 2011;103:1827-1839.
4. Rehm J, Mathers C, Popova S, Thavorncharoensap M, Teerawattananon Y, Patra J. Global burden of disease and injury and economic cost attributable to alcohol use and alcohol-use disorders. Lancet 2009;373:2223-2233.

5. Liang H, Wang J, Xiao H, et al. Estimation of cancer incidence and mortality attributable to alcohol drinking in China. BMC Public Health 2010;10:730.

6. Nelson DE, Jarman DW, Rehm J, et al. Alcohol-attributable cancer deaths and years of potential life lost in the United States. Am J Public Health 2013;103:641-648.

7. Athar M, Back JH, Tang X, et al. Resveratrol: a review of preclinical studies for human cancer prevention. Toxicol Appl Pharmacol 2007;224:274-283.

8. Patel KR, Scott E, Brown VA, Gescher AJ, Steward WP, Brown K. Clinical trials of resveratrol. Ann N Y Acad Sci 2011;1215:161169.

9. Choi YJ, Lee DH, Han KD, et al. The relationship between drinking alcohol and esophageal, gastric or colorectal cancer: a nationwide population-based cohort study of South Korea. PLoS One 2017;12:e0185778

10. Testino G. The burden of cancer attributable to alcohol consumption. Maedica (Buchar) 2011;6:313-320.

11. Stickel F, Schuppan D, Hahn EG, Seitz HK. Cocarcinogenic effects of alcohol in hepatocarcinogenesis. Gut 2002;51:132-139.

12. Singal AK, Anand BS. Mechanisms of synergy between alcohol and hepatitis C virus. J Clin Gastroenterol 2007;41:761-772.

13. Donato F, Gelatti U, Limina RM, Fattovich G. Southern Europe as an example of interaction between various environmental factors: a systematic review of the epidemiologic evidence. Oncogene 2006;25:3756-3770.

14. Turati F, Galeone C, Rota M, et al. Alcohol and liver cancer: a systematic review and meta-analysis of prospective studies. Ann Oncol 2014;25:1526-1535.

15. Dietary guidelines for American 2015-2020 [Internet]. Rockville: U.S. Department of Health and Human Services and U.S. Department of Agriculture; c2015 [cited 2020 Feb 10]. Available from: https://health.gov/dietaryguidelines/2015/guidelines/.

16. Moher D, Liberati A, Tetzlaff J, Altman DG; PRISMA Group. Preferred reporting items for systematic reviews and meta-analyses: the PRISMA statement. PLoS Med 2009;6:e1000097.

17. Stang A. Critical evaluation of the Newcastle-Ottawa scale for the assessment of the quality of nonrandomized studies in metaanalyses. Eur J Epidemiol 2010;25:603-605.

18. DerSimonian R, Laird N. Meta-analysis in clinical trials. Control Clin Trials 1986;7:177-188.

19. Higgins JP, Thompson SG, Deeks JJ, Altman DG. Measuring inconsistency in meta-analyses. BMJ 2003;327:557-560.

20. Egger M, Davey Smith G, Schneider M, Minder C. Bias in metaanalysis detected by a simple, graphical test. BMJ 1997;315:629634.

21. Shimazu T, Sasazuki S, Wakai K, et al. Alcohol drinking and primary liver cancer: a pooled analysis of four Japanese cohort stud- 
ies. Int J Cancer 2012;130:2645-2653.

22. Persson EC, Schwartz LM, Park Y, et al. Alcohol consumption, folate intake, hepatocellular carcinoma, and liver disease mortality. Cancer Epidemiol Biomarkers Prev 2013;22:415-421.

23. Allen NE, Beral V, Casabonne D, et al. Moderate alcohol intake and cancer incidence in women. J Natl Cancer Inst 2009;101:296305.

24. Schwartz LM, Persson EC, Weinstein SJ, et al. Alcohol consumption, one-carbon metabolites, liver cancer and liver disease mortality. PLoS One 2013;8:e78156.

25. Kawamura Y, Arase Y, Ikeda K, et al. Effects of alcohol consumption on hepatocarcinogenesis in Japanese patients with fatty liver disease. Clin Gastroenterol Hepatol 2016;14:597-605.

26. Setiawan VW, Wei PC, Hernandez BY, et al. Disparity in liver cancer incidence and chronic liver disease mortality by nativity in Hispanics: the multiethnic cohort. Cancer 2016;122:1444-1452.

27. Michikawa T, Inoue M, Sawada N, et al. Development of a prediction model for 10-year risk of hepatocellular carcinoma in middleaged Japanese: the Japan Public Health Center-based Prospective Study Cohort II. Prev Med 2012;55:137-143.

28. Chen CJ, Wang LY, Lu SN, et al. Elevated aflatoxin exposure and increased risk of hepatocellular carcinoma. Hepatology 1996;24:38-42.

29. Ohishi W, Fujiwara S, Cologne JB, et al. Risk factors for hepatocellular carcinoma in a Japanese population: a nested case-control study. Cancer Epidemiol Biomarkers Prev 2008;17:846-854.

30. Koh WP, Robien K, Wang R, Govindarajan S, Yuan JM, Yu MC. Smoking as an independent risk factor for hepatocellular carcinoma: the Singapore Chinese Health Study. Br J Cancer 2011;105:1430-1435.

31. Trichopoulos D, Bamia C, Lagiou P, et al. Hepatocellular carcinoma risk factors and disease burden in a European cohort: a nested case-control study. J Natl Cancer Inst 2011;103:1686-1695.

32. Yuan JM, Govindarajan S, Arakawa K, Yu MC. Synergism of alcohol, diabetes, and viral hepatitis on the risk of hepatocellular carcinoma in blacks and whites in the U.S. Cancer 2004;101:10091017.

33. Loftfield E, Freedman ND, Lai GY, et al. Higher glucose and insulin levels are associated with risk of liver cancer and chronic liver disease mortality among men without a history of diabetes. Cancer Prev Res (Phila) 2016;9:866-874.

34. Yi SW, Choi JS, Yi JJ, Lee YH, Han KJ. Risk factors for hepatocellular carcinoma by age, sex, and liver disorder status: a prospective cohort study in Korea. Cancer 2018;124:2748-2757.

35. Kim MK, Ko MJ, Han JT. Alcohol consumption and mortality from all-cause and cancers among 1.34 million Koreans: the results from the Korea national health insurance corporation's health examinee cohort in 2000. Cancer Causes Control 2010;21:22952302.

36. Yi SW, Sull JW, Linton JA, Nam CM, Ohrr H. Alcohol consump- tion and digestive cancer mortality in Koreans: the Kangwha Cohort Study. J Epidemiol 2010;20:204-211.

37. Yang L, Zhou M, Sherliker P, et al. Alcohol drinking and overall and cause-specific mortality in China: nationally representative prospective study of 220,000 men with 15 years of follow-up. Int J Epidemiol 2012;41:1101-1113.

38. Jee SH, Ohrr H, Sull JW, Samet JM. Cigarette smoking, alcohol drinking, hepatitis B, and risk for hepatocellular carcinoma in Korea. J Natl Cancer Inst 2004;96:1851-1856.

39. Joshi S, Song YM, Kim TH, Cho SI. Socio-economic status and the risk of liver cancer mortality: a prospective study in Korean men. Public Health 2008;122:1144-1151.

40. Jung EJ, Shin A, Park SK, et al. Alcohol consumption and mortality in the Korean Multi-Center Cancer Cohort Study. J Prev Med Public Health 2012;45:301-308.

41. Kono S, Ikeda M, Tokudome S, Nishizumi M, Kuratsune M. Alcohol and mortality: a cohort study of male Japanese physicians. Int J Epidemiol 1986;15:527-532.

42. Park SM, Lim MK, Shin SA, Yun YH. Impact of prediagnosis smoking, alcohol, obesity, and insulin resistance on survival in male cancer patients: National Health Insurance Corporation Study. J Clin Oncol 2006;24:5017-5024.

43. Shih WL, Chang HC, Liaw YF, et al. Influences of tobacco and alcohol use on hepatocellular carcinoma survival. Int J Cancer 2012;131:2612-2621.

44. Yi SW, Hong JS, Yi JJ, Ohrr H. Impact of alcohol consumption and body mass index on mortality from nonneoplastic liver diseases, upper aerodigestive tract cancers, and alcohol use disorders in Korean older middle-aged men: prospective cohort study. Medicine (Baltimore) 2016;95:e4876.

45. Younoszai Z, Li Z, Stepanova M, Erario M, Cable R, Younossi ZM. Statin use is not associated with liver related mortality. Ann Hepatol 2014;13:84-90.

46. Fuchs CS, Stampfer MJ, Colditz GA, et al. Alcohol consumption and mortality among women. N Engl J Med 1995;332:1245-1250.

47. Marugame T, Yamamoto S, Yoshimi I, et al. Patterns of alcohol drinking and all-cause mortality: results from a largescale population-based cohort study in Japan. Am J Epidemiol 2007;165:1039-1046

48. Ferrari P, Licaj I, Muller DC, et al. Lifetime alcohol use and overall and cause-specific mortality in the European Prospective Investigation into Cancer and nutrition (EPIC) study. BMJ Open 2014;4:e005245.

49. Saito E, Inoue M, Sawada N, et al. Impact of alcohol intake and drinking patterns on mortality from all causes and major causes of death in a Japanese population. J Epidemiol 2018;28:140-148.

50. Chuang SC, Lee YC, Wu GJ, Straif K, Hashibe M. Alcohol consumption and liver cancer risk: a meta-analysis. Cancer Causes Control 2015;26:1205-1231. 